\title{
COVID-19 Dashboard Experiences - Lessons learned
}

\author{
Gerd Buziek ${ }^{\mathrm{a}, *}$ \\ ${ }^{a}$ Business Relations Executive, Esri Deutschland GmbH, Kranzberg, Gerd Buziek-g.buziek@esri.de \\ * Corresponding author
}

Keywords: COVID-19, Corona, Dashboard, Open Data, Spatial Infrastructure, GIS

\section{Abstract:}

As of March 2020, Esri Germany administers the Berlin based Robert Koch-Institute official COVID-19 Dashboard (Figure 1). During Esri's evolvement both, organizational and technical processes have had to be built from scratch. Our objective was to keep society, as well as the disaster response units 24/7 informed about the spatiotemporal patterns of Corona pandemic. To achieve this several challenges had to be overcome. These challenges ranged from data gathering to data dissemination, from the delivery of COVID-19 information to the general public, as well as to the crisis prevention teams, and from the communication to individuals as well as to various specialists such as data journalists. Having a COVID-19 dashboard online results in a lot of publicity to the provider, but also requires a lot of effort to deliver a reliable and sustainable COVID-19 service, as many external decision making processes depend on the dashboard and the data which drives it. This presentation is not only about how we provided this service but will also include a look at the lessons learnt and how we can be best prepared for future spatiotemporal phenomena to help crisis response and perhaps even prevention.

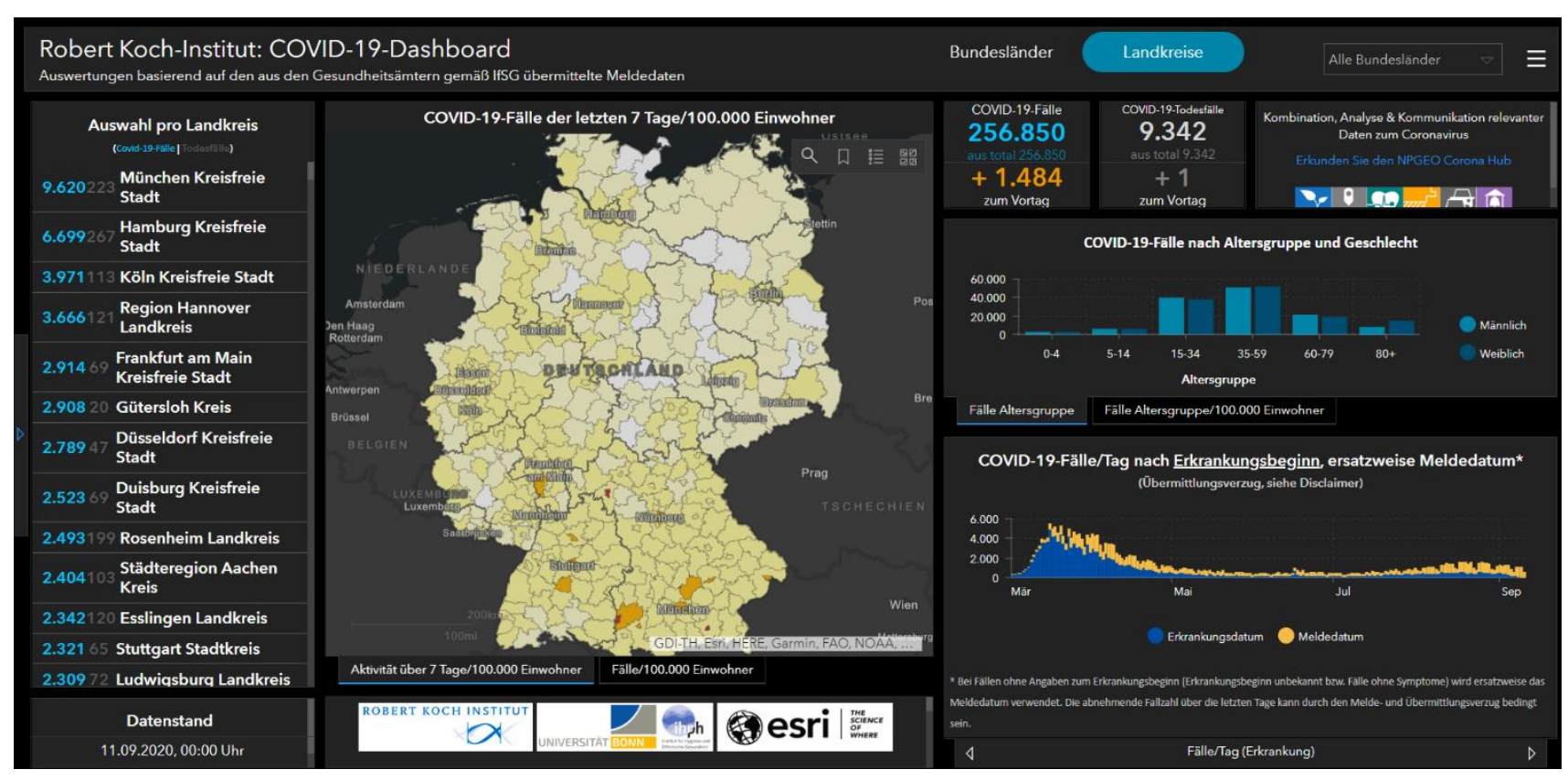

Figure 1. Robert Koch-Institut COVID-19 Dashboard

\section{Acknowledgements}

I like to thank all members of the Corona Taskforce from Esri Germany/Switzerland for their very valuable contributions and the great cooperation. 